\title{
MODEL PEMBELAJARAN EXPERIENTIAL KOLB UNTUK MENINGKATKAN PEMAHAMAN KONSEP SISWA PADA MATA PELAJARAN FISIKA
}

Eidel weis Dewi Jannati, M.Pd.

Fakulas Teknik, Universitas Majalengka eidelweis unma@yahoo.com

\begin{abstract}
Based on the results of preliminary studies, Physics learning process at school as the place to research have using conventional learning models, on the learning process of students tend to be passive. As a result, understanding of concepts was very low. Therefore, be required a proper and appropriate learning model. Experiential Kolb learning models can be an alternative learning model to applied,because in this model, students required to actively and creatively to construct knowledge. The purpose of this research is knowing an improved understanding of the concept, after application Experiential Kolb learning model on the concept optical devices. The design of this research using Control Group Pretest-Potstest Design with experiment sample high school students grade $x$ at Majalengka citty. The results showed that the understanding of concepts have increase significantly viewed of the value of $N$-gain after application Experiential Kolb learning model. Based on the analysis of data obtained by the average of the value of understanding $\mathrm{N}$-gain is 0,62 for the class have used Experiential Kolb learning model and 0,38 for the class have used conventional learning. It can be concluded that the Experiential Kolb learning model can further improve the understanding of concepts compared with conventional learning. Results of an analysis of student responses showed that students had a positive response to the application Experiential Kolb learning models.
\end{abstract}

Keywords : Experiential Kolb learning models, understanding of concepts.

\section{PENDAHULUAN}

Proses pembelajaran IPA menekankan pada pemberian pengalaman langsung untuk mengembangkan kompetensi agar peserta didik menjelajahi dan memahami alam sekitar secara ilmiah. Pendidikan IPA diarahkan untuk memperoleh pemahaman yang lebih mendalam tentang alam sekitar (Depdiknas, 2006). Salah satu cabang IPA adalah Fisika. Oleh karena itu siswa perlu memahami konsep Fisika secara lebih mendalam agar mampu menye lesaikan masalah atau mengaflikasikannya dalam kehidupan sehari-hari. Pemahaman konsep merupakan pemahaman tentang hal-hal yang berhubungan dengan konsep, yaitu arti, sifat, dan uraian suatu konsep dan juga kemampuan dalam menjelaskan teks, diagram, dan fenomena yang melibatkan konsep-konsep pokok yang bersifat abstrak dan teori-teori dasar sains.

Selain itu, KTSP memberi penekanan atau memfokuskan pada siswa sehingga akan membawa konsekuensi yang luas. Selain siswa menguasai materi fisika, siswa diharapkan juga dapat mengembangkan jati dirinya, mengenal lingkungannya, dapat bersosialisasi dengan lingkungan dan juga peka terhadap lingkungan serta tahu akan hak dan kewajibannya. Dengan demikian, belajar tidak hanya berlangsung di dalam lingkungan sekolah, tetapi juga dapat berlangsung di luar sekolah, di masyarakat, alam sekitar, untuk dapat mengembangkan kreativitas siswa sendiri. Disini siswa ditekankan harus mampu menjelaskan fenomena-fenomena fisis dalam kehidupannya sehari-hari, sehingga dengan itu pembelajaran menjadi bermanfaat, tidak hanya mendengarkan ceramah dari guru akan tetapi mereka mengetahui atau mampu menjelaskan fenomena fisis dalam kehidupan sehari-hari.

Berdasarkan hasil studi kasus yang peneliti lakukan pada salah satu SMA Negeri di Majalengka, diperoleh hasil bahwa kebanyakan siswa waktu di kelas hanya mendengarkan guru mengajar, mengerjakan soal-soal yang diberikan oleh guru. Dengan demikian, siswa belajar lebih pasif dan mereka tidak mampu menerapkan dalam kehidupan sehari-hari. Seiring dengan hal itu, pemahaman konsep siswa pun tergolong rendah. Hal ini, terbukti dari data hasil ujian akhir semester ganjil di salah satu SMA Negeri di Majalengka memperoleh hasil rata-rata 60 , sementara itu nilai Kriteria Ketuntasan Minimum (KKM) di sekolah tersebut yaitu 80. Sehingga dapat dikatakan siswa masih kurang memahami konsep Fisika yang telah dijelaskan di dalam kelas. Rendahnya pemahaman konsep ini bisa dipengaruhi oleh banyak faktor. 
Garis besar dari apa yang diungkapkan salah satu pengajar yang diperoleh hasil: Siswa sulit memahami konsep-konsep dari materi yang disampaikan; siswa bersifat pasif, hanya mendengarkan ceramah dari pengajar.

Dari pernyataan diatas siswa tidak mampu memahami konsep fisika. Padahal, pembelajaran sain akan bermakna dan bermanfaat apabila siswa mampu menerapkan dalam kehidupannya. Hal tersebut diperkuat pernyataan mata pelajaran akan tambah berarti jika siswa mempelajari materi yang disajikan melalui konteks kehidupan mereka dan menemukan arti dalam proses pembelajaran sehingga belajar akan lebih bermakna dan menyenangkan (Sanjaya,2009).

Kelemahan lain dari pembelajaran fisika di sekolah adalah guru hanya menampilkan produk IPA berupa rumus-rumus fisika yang rumit tanpa. Hal ini membuat siswa takut dan tidak menyukai Fis ika pada akhirnya siswa tidak mampu memahami konsepnya. Tentunya tidak sesuai dengan tuntunan pendidikan IPA, dalam hal ini fisika, tidak hanya untuk meningkatkan pengetahuan dan pemhaman konsep saja, tetapi dapat menerapkan dalam kehidupan sehari-hari. Hal ini sejalan dengan pernyataan yang dikemukakan oleh Sanjaya (2006) bahwa salah satu masalah yang dihadapi di dunia pendidikan saat ini adalah masalah lemahnya proses pembelajaran. Dalam proses pembelajaran, anak kurang didorong untuk mengembangkan kemampuan berfikir. Proses pembelajaran di kelas menuntut siswa untuk menghapal informasi, mengingat dan menimbun berbagai informasi tanpa dituntut untuk memahami informasi yang diingatnya itu untuk dikaitkan dengan kehidupan sehari-hari. Sehingga dengan lemahnya proses pembelajaran maka semakin banyak siswa yang akan kesulitan memahami konsep-konsep Fisika.

Salah satu model pembelajaran yang mendukung untuk menyelesaikan permasalahan diatas yaitu model pembelajaran Experiential Kolb (Manolas, 2005). Model pembelajaran ini menyajikan empat tahapan yaitu pengalaman kongkrit (concrete experience) bagi siswa sebagai awal pembelajaran. Pada tahap ini siswa secara individu menekankan pada pembelajaran berpikir terbuka dan kemampuan beradaftasi daripada pendekatan sistematik pada situasi masalah. Tahap kedua yaitu pengamatan reflektif (reflective observation). Pada tahap ini siswa mengamati demonstrasi sederhana serta mencoba mengeluarkan pendapat mengapa dan bagaimana hal tersebut terjadi. Tahap ketiga yaitu konsepsi abstrak (abstrak conceptualization). Pada tahap ini menjadi mengerti konsep secara umum dengan tahap pertama dan kedua sebagai acuan. Konsepsi abstrak mengharuskan siswa untuk menggunakan logika dan pikiran untuk memahami situasi dan masalah. Kemudian diselesaikan melalui percobaan aktif (active experimentation). Pada tahap ini siswa menggunakan teori yang mereka dapat selama konsepsi abstrak untuk membuat prediksi. Melalui pembelajaran ini diharapkan dapat membangun konsep yang bermakna dan kepercayaan diri dalam memecahkan masalah dan membuat keputusan yang cermat.

Penelitian terhadap model pembelajaran Experiential Kolb dilakukan oleh Manolas (2005) menunjukkan bahwa model pembelajaran Experiential Kolb dapat menstimulasi siswa untuk memilih pembelajaran dan menantang mereka untuk membangun kemampuan dalam mengefektifkan pemikiran dan pemecahan masalah. Untuk itu, peneliti bermaksud menerapkan suatu pembelajaran yang melibatkan siswa untuk mencari pengetahuannya sendiri dan penguasaan konsep melalui model pembelajaran tersebut pada konsep alat optik.

Salah satu konsep yang ada dalam materi ajar Fisika di SMA pada kelas $\mathrm{X}$ adalah alat optik. Konsep alat optik berkaitan erat dengan kehidupan sehari-hari siswa dan sering mereka gunakan dalam keseharian ataupun dalam kegiatan-kegiatan tertentu. Siswa kerap menghadapi masalah mengenai alat optik sehingga dapat diangkat basis dari suatu pembelajaran. Melalui penggunaan model pembelajaran Experiential Kolb diharapkan siswa mempelajari konsep alat optik tidak hanya menghapal konsep-konsep saja tetapi siswa secara aktif membangun sendiri pengetahuannya melalui pemecahan masalah. Dengan demikian pembelajaran yang digunakan dapat meningkatkan pemahaman konsep.

\section{METODE PENELITIAN}

Desain eksperimen yang digunakan adalah "pretest-posttest control group design" (Sukmadinata, 2009:208) dimana penentuan kelas kontrol dilakukan secara acak perkelas. Eksperimen dilakukan dengan memberikan perlakuan pembelajaran dengan model pembelajaran Experiential Kolb pada kelompok eksperimen dan pembelajaran konvensional pada kelompok kontrol.

Populasi dalam penelitian ini adalah seluruh siswa kelas $X$ yang terdiri dari 10 kelas pada salah satu SMA Negeri di Majalengka tahun ajaran 20122013. Sedangkan pengambilan sampel dilakukan dengan teknik simple random sampling karena pengambilan sampel secara acak tanpa memperhatikan strata yang ada dalam populasi (Sugiono, 2006: 57). 
Untuk mengetahui kelayakan instrumen dilakukan judgement oleh dosen ahli, kemudian uji coba soal pemahaman konsep dan kemampuan menjelaskan fenomena fisis. Hasil uji coba soal dianalisis terlebih dahulu untuk mengetahui kelayakan instrumen yang digunakan meliputi perhitungan Validitas Instrumen, Reliabilitas Instrumen, Tingkat Kesukaran, dan Daya Pembeda Butir Soal. Instrumen yang digunakan yaitu: (1) tes pemahaman konsep berupa tes tertulis pilihan ganda sebanyak 14 butir soal, (2) lembar observasi keterlaksanaan model, dan (3) tes skala sikap untuk menjaring tanggapan siswa terhadap model pembelajaran experiential Kolb.

Untuk melihat signifikansi perbedaan dua rata-rata antara nilai pretest dan posttes menggunakan Microsoft office excel 2010. Kemudian dihitung N-Gain dari hasil pretest dan posttes tersebut. Pengolahan data rata-rata skor gain dinormalisasi dianalisis secara statistik dengan menggunakan software Microsoft Office Excel 2010. Sebelum dilakukan uji hipotesis, perlu dilakukan uji normalitas distribusi data dengan menggunakan menggunakan Saphiro Wilk dan uji homogenitas variansi data menggunakan statistik uji Levene, jika data tidak terdistribusi normal maka dilakukan uji mann whitney menggunakan SPSS versi 17 , sedangkan untuk presentase keterlaksanaan model Hasil dari observasi dikumpulkan, disusun dan dikelompokkan. Informasi yang diperoleh diinterprestasikan dan kemudian disimpulkan. Angket menggunakan tes skala likert.

\section{HASIL PENELITIAN} PEMBAHASAN

\section{1) Peningkatan Pemahaman Konsep Sis wa}

Diagram persentase perbandingan skor rata-

rata pretest, pos-test, dan $\mathrm{N}$-gain pemahaman konsep materi alat optik antara kelas eksperimen dan kelas kontrol disajikan dalam diagram pada Gambar 1.

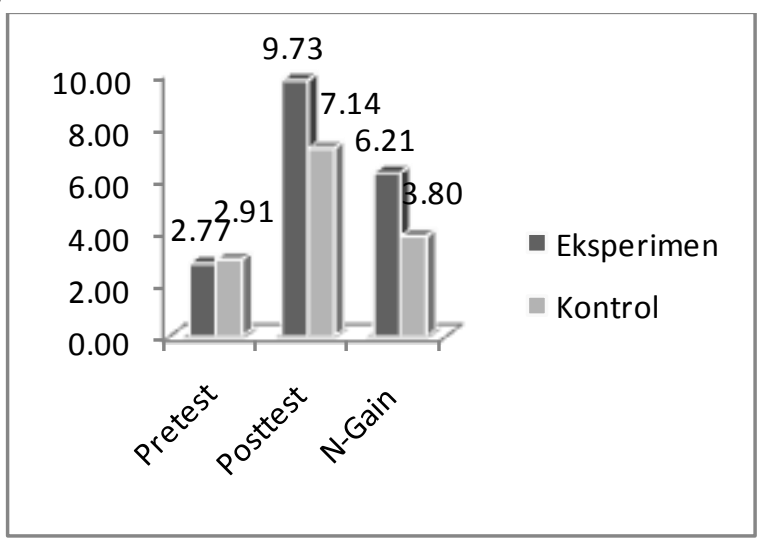

Gambar 1. Presentase Perbandingan Skor Rata-rata pre-test, post-test, dan Gain yang dinormalisasi pemahaman konsep siswa pada Kedua Kelas

Perbandingan rata-rata $\mathrm{N}$-gain untuk setiap indikator pemahaman konsep ditunjukkan oleh diagram batang pada Gambar 2 .

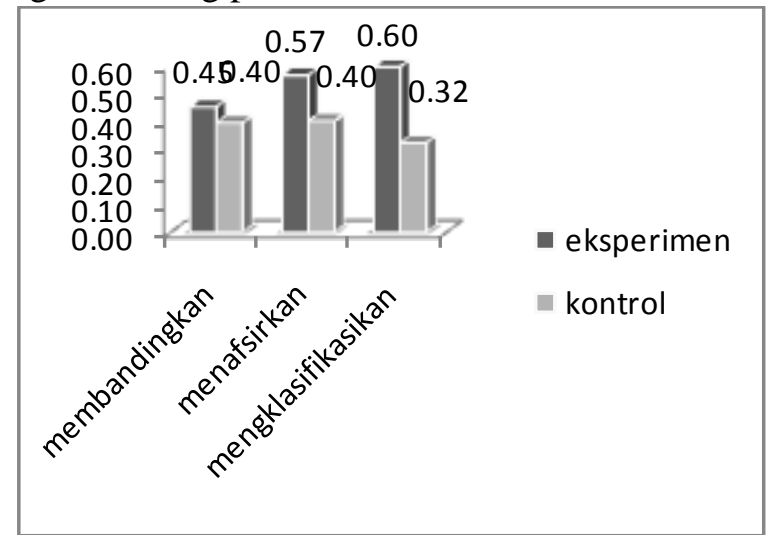

Gambar 2. Diagram batang perbandingan $N$-gain indikator pemahaman Konsep

Berdasarkan Gambar 2 perolehan rata-rata gain yang dinormalisasi pemahaman konsep siswa untuk setiap indikator pada pembelajaran dengan model pembelajaran Experiential Kolb lebih tinggi dibandingkan dengan pembe lajaran konvensional.

Uji normalitas distribusi data dengan jumlah sampel 30 dan taraf taraf kepercayaan 0,95 terhadap kelas eksperimen diperoleh sig 0,121>0,05, berarti bahwa data pada kelas eksperimen berdistribusi normal. Uji homogenitas rata-rata gain yang dinormalisasi dengan menggunakan SPSS 17 diperoleh nilai sig $0,376>0,05$ untuk derajat kebebasan df $1=1$ dan df2 $=50$ dengan tingkat kepercayaan 0,95. Sehingga dapat disimpulkan bahwa kedua kelompok memiliki variansi yang homogen. Diperoleh nilai $p$-value sebesar 0,000. Untuk menguji hipotesis ini menggunakan uji-t satu pihak, maka nilai signifikansi merupakan setengah dari nilai $p$-value (2-tailed) (Uyanto, 2009). Maka tahap selanjutnya mencari nilai signifikansi dengan cara nilai signifikansi $p$-value $(1$-tailed $)=\frac{1}{2} p$-value (2-tailed). Kriteria uji yang digunakan adalah tolak $\mathrm{H}_{0}$ jika $\frac{1}{2}$ p-value $(2$-tailed $)<\alpha(0,05)$ dan $\mathrm{H}_{0}$ ditolak untuk kondisi lainnya maka $\mathrm{H}_{1}$ diterima. Kesimpulan yang dapat diperoleh dari hasil uji-t ini adalah bahwa penerapan model pembelajaran Experiential Kolb dapat meningkatkan pemahaman konsep siswa dibandingkan dengan penerapan model konvensional.

Pada indikator membandingkan, perbedaan $\mathrm{N}$ gainnya tidak terlalu jauh berbeda. Ini dikarenakan siswa pada tahapan-tahapan model eksperiential Kolb di awal pertemuan masih banyak yang belum terbiasa. Pada tahapan pengalaman kongkrit, 
pengamatan reflektif, konseptualisasi abstrak dan percobaan aktif yang di dalamnya melatihkan pemahaman konsep indikator membandingkan masih belum dapat terlaksana dengan baik.

Peningkatan pemahaman konsep tertinggi pada indikator mengklasifikasikan untuk kelas eksperimen dengan nilai 0,60 . Hal ini dimungkinkan karena dalam penelitian ini kelas eksperimen menggunakan model pembelajaran Experiential Kolb. Model pembelajaran Experiential Kolb memberikan peluang pada siswa untuk mengemukakan pengalaman sehari-hari sebagai dasar dalam memahami konsep yang pada akhirnya siswa mampu mengklasifikasikan pada pembelajaran alat optik. Pengamatan reflektif menjadikan siswa lebih leluasa dalam belajar secara mandiri, saling bertukar pikiran dengan sesamanya dalam melakukan eksperimen. Disini siswa dituntut untuk aktif dalam pembelajaran. Hal ini sejalan dengan pandangan yang dikemukakan oleh Nur dan Wikandari (2000) bahwa guru dapat membantu siswa dalam mengkontruksi pengetahuannya, dengan cara-cara mengajar yang membuat informasi yang diberikan guru menjadi sangat bermakna dan relevan bagi siswa, dan dengan memberikan kesempatan kepada siswa untuk menemukan dan menetapkan ide-ide mereka sendiri untuk belajar.

Secara garis besar penggunaan model pembelajaran Experiential Kolb ternyata lebih mampu meningkatkan pemahaman konsep siswa terhadap materi yang diajarkan yaitu materi alat optik. Hal ini disebabkan karena pada model pembelajaran Experiential Kolb, siswa diajak untuk memahami konsep melalui pengalaman kongkrit yang menekankan keterlibatan aktif dan pembelajaran dengan pengalaman. Tahapan yang membedakan antara kelas eksperimen dengan kelas kontrol adalah pada fase pengamatan reflektif dan konsepsi abstrak. Pada fase ini siswa diajak untuk mengamati fenomena dan mencoba untuk mengajukan hipotesis terhadap pengamatan yang telah dilakukan. Pada akhirnya siswa diarahkan untuk membuktikan hipotesis yang telah diajukan melalui percobaan aktif. Melalui tahapan-tahapan inilah pemahaman siswa terhadap konsep yang diajarkan lebih signifikan dibanding ke las kontrol.

Hasil pengujian hipotesis menunjukkan bahwa penerapan model pembelajaran Experiential Kolb lebih efektif dalam meningkatkan pemahaman konsep dibandingkan penerapan model pembelajaran konvensional. Model Experiential Kolb yang diterapkan pada kelas eksperimen dapat menggali pengalaman siswa sebagai modal dasar dalam penemuan konsep-konsep baru. Hal ini senada dengan pernyataan Ausubel (Dahar, 1996) yang menyatakan bahwa agar sebuah pembelajaran menjadi bermakna, maka konsep baru atau informasi baru yang hendak diperoleh siswa harus dikaitkan dengan konsep-konsep yang telah ada dalam struktur kognitif siswa. Selain itu, model pembelajaran Experiential Kolb melatih kemampuan siswa untuk merumuskan hipotesis melalui kegiatan percobaan, sehingga setelah melalui proses pembelajaran ini siswa dapat memahami konsep yang dipelajari.

\section{2) Tanggapan Sis wa te rhadap Pembelajaran}

Berdasarkan hasil analis is angket tanggapan siswa terhadap model pembelajaran experiential Kolb, dapat disimpulkan bahwa siswa memberikan tanggapan positif (baik) terhadap model pembelajaran experiential Kolb yang diterapkan pada pembelajaran konsep alat optik. Berdasarkan data yang diperoleh, sebesar $80 \%$ siswa menyatakan setuju bahwa model pembelajaran Experiential Kolb yang digunakan adalah model pembelajaran baru, $82 \%$ siswa menyatakan bahwa cara guru bertanya dapat memotivasi siswa dalam mencari tahu jawaban, $83 \%$ siswa menyatakan bahwa kegiatan diskusi membuat siswa lebih menghargai pendapat orang lain. Sebesar $37 \%$ siswa merasa model pembelajaran yang digunakan sama dengan model yang digunakan pada model pembelajaran sebelumnya, $40 \%$ siswa menyatakan model pembelajaran eksperiential Kolb yang diterapkan membuat sulit dalam memahami konsep dan 38\% menyatakan bahwa pembelajaran secara keseluruhan sangat membosankan.

Model pembe lajaran yang diterapkan menurut siswa sangat menyenangkan sehingga siswa menjadi lebih termotivasi untuk belajar dan menginginkan agar dapat diterapkan pada pembelajaran materi yang lain. Tahap-tahap pembelajaran experiential Kolb mampu menggali pemhaman konsep siswa dan melatih kemampuan menjelaskan fenomena fisis. Dengan demikian siswa lebih termotivasi dalam belajar

\section{KESIMPULAN}

Berdasarkan hasil penelitian, analisis data, dan pembahasan yang telah dikemukakan pada bab sebelumnya, maka dapat disimpulkan bahwa: (1) Penerapan model pembelajaran Experiential Kolb secara signifikan dapat lebih meningkatkan pemahaman konsep siswa dibandingkan dengan model konvensional. (2) Siswa memberikan tanggapan positif terhadap penerapan model pembelajaran Experiential Kolb pada materi alat optik.

\section{DAFTAR PUSTAKA}


1. Dahar, R. W. (1989). Teori-Teori Belajar. Jakarta: Erlangga.

2. Depdiknas. (2006). Kurikulum Tingkat Satuan Pendidikan Sekolah Menengah Atas. Jakarta: Depdiknas.

3. Manolas, E.I. (2005). “Kolb's Experiential Learning Model: Enlivening Physics Courses inPrimary Education". The Internet TESL Journal. 3,(9)

4. Nur, Mohammad, dan Prima Retno Wikandari.(2000). Pengajaran Berpusat Kepada Siswa dan Pendekatan Konstruktivis dalam Pengajaran. Surabaya: UNESA Press.

5. Robert, J.Y. dan Christopher, M.C. (1981). “ Reflective Journal Writing: Theori and Practice". The Institute for research on Teaching Ericson Hall Michigan State University. 1-34.

6. Sanjaya, W. (2008). Strategi Pembelajaran Berorientasi Standar Proses Pendidikan. Jakarta:Prenada Media.

7. Sugiyono. (2006). Statistika untuk Penelitian. Bandung: Alfabeta.

8. Sukmadinata, N.S. (2009). Metode Penelitian Pendidikan. Bandung: PPS UPI dan Remaja Rosdakarya.

9. Sutawidjaja, Akbar. (1991). PenggunaanAlat Peraga Dalam Pengajaran Matematika Di Sekolah Dasar. Jakarta: Penataran Penyiapan Calon Penatar (PCP) Dosen PGSD-D II Guru Kelas. 